\title{
Transcript profiling of genes expressed during fibre development in diploid cotton (Gossypium arboreum L.)
}

\author{
Atul S. Hande ${ }^{1}$, Ishwarappa S. Katageri ${ }^{*}$, Mangesh P. Jadhav' ${ }^{1}$ Sateesh Adiger ${ }^{1}$, Savita Gamanagatti ${ }^{1}$, \\ Kethireddy Venkata Padmalatha², Gurusamy Dhandapani ${ }^{2}$, Mogilicherla Kanakachari², \\ Polumetla Ananda Kumar ${ }^{2}$ and Vanga Siva Reddy ${ }^{3}$
}

\begin{abstract}
Background: Cotton fibre is a single cell and it is one of the best platforms for unraveling the genes express during various stages of fibre development. There are reports devoted to comparative transcriptome study on fiber cell initiation and elongation in tetraploid cultivated cotton. However, in the present investigation, comparative transcriptome study was made in diploid cultivated cotton using isogenic fuzzy-lintless (FI) and normal fuzzy linted (FL) lines belong to Gossypium arboreum, diploid species at two stages, 0 and $10 \mathrm{dpa}$ (days post anthesis), using Affymetrix cotton GeneChip genome array.

Result: Scanning electron microscopy (SEM) analysis uncovered the occurrence of few fibre cell initials in the Fl line as compared to many in Normal $F L$ at -2 and $0 \mathrm{dpa}$. However, at $10 \mathrm{dpa}$ there were no fibre cells found elongated in $\mathrm{Fl}$ but many elongated cells were found in $\mathrm{FL}$ line. Up-regulation of transcription factors, AP2-EREBP, $\mathrm{C} 2 \mathrm{H} 2, \mathrm{C} 3 \mathrm{H}$, $\mathrm{HB}$ and WRKY was observed at 0 dpa whereas in 10 dpa transcription factors, AP2-EREBP, AUX/IAA, bHLH, C2H2, $\mathrm{C} 3 \mathrm{H}, \mathrm{HB}, \mathrm{MYB}, \mathrm{NAC}$, Orphans, PLATZ and WRKY were found down regulated in Fl line. These transcription factors were mainly involved in metabolic pathways such as phytohormone signaling, energy metabolism of cell, fatty acid metabolism, secondary metabolism and other signaling pathways and are related directly or indirectly in fiber development. Quantitative real-time PCR was performed to check fold up or down-regulation of these genes and transcription factors (TFs) down regulated in mutants as compared to normal at 0 and $10 \mathrm{dpa}$.

Conclusion: This study elucidates that the up-regulation of transcription factors like AP2-EREBP, C2H2, C3H, HB, WRKY and phytohormone signaling genes at $0 \mathrm{dpa}$ and their down-regulation at the $10 \mathrm{dpa}$ might have constrain the fibre elongation in fuzzy-lintless line. Along with this the down-regulation of genes involved in synthesis of VLCFA chain, transcripts necessary for energy and cell wall metabolism, EXPANSINs, arabinogalactan proteins (AGPs), tubulin might also be the probable reason for reduced growth of fibres in the FI. Plant receptor-like kinases (RLKs), Leucine Rich Repeats) LRR- family protein and signal transduction coding for mitogen-activated protein kinase (MAPK) cascade, have been engaged in coordination of cell elongation and SCW biosynthesis, down-regulation of these might loss the function leads to reduced fibre growth.
\end{abstract}

Keywords: Diploid cotton, Microarray, qRT PCR, Transcription factors

\footnotetext{
* Correspondence: katageriis@uasd.in

${ }^{1}$ University of Agricultural Sciences, Dharwad, Karnataka, India

Full list of author information is available at the end of the article
} 


\section{Background}

Cotton fibre is one of the prime naturally available raw materials for textile industry. It serves as mainstays for global economy with more than $50 \%$ share of raw material. Among all the 50 species of Gossypium L. only four species are widely accepted as cultivated, two of these are diploid $(2 \mathrm{n}=26)$ and two are allotetraploid $(2 n=52)[1-3]$. The bulk of world's cotton is supplied by modem cultivars (Upland cotton) of Gossypium hirsutum, represents $90 \%$ of the worlds' cultivated cotton; Gossypium barbadanse represents $8 \%$ and diploid cotton from the old world i.e., Gossypium arboreum and Gossypium herbaceum represents remaining 2\% [2, 3]. Cotton fibre is the longest single-celled outgrowths in higher plants from individual epidermal cells on the outer integument of developing cotton fruit ovules [3-5]. Cotton fibres of Gossypium hirsutum range between 30 and $40 \mathrm{~mm}$ in length and $\sim 15 \mu \mathrm{m}$ in thickness $[4,5]$. Recent findings depicts that the cotton is considered as model plant in cell development study and has one of the best characterized single-celled genomics platforms to date $[6,7]$. Fibre development in cotton proceeds through a number of distinctive but overlapping stages: fibre initiation, fibre elongation, secondary cell wall deposition (SCWD) [8] and maturation/dehydration [6, 9-11]. In fibre initiation, which occurs around the time of anthesis (from -3 to $+1 \mathrm{dpa}$ ), although all the cells have potential to undergo morphogenesis and productively differentiate into mature fibres, only $30 \%$ becomes mature fibre [11, 12]. Fibre elongation ( 0 to $\sim 25 \mathrm{dpa}$ ) greatly affected by creating and maintaining high turgor pressure within the cells with peak growth rate of $2 \mathrm{~mm}$ /day until the fibre gain its final length [13-15]. During the period of secondary cell wall (SCW) biogenesis ( 21 to 45 dpa), $90 \%$ of cellulose microfibrils deposit on cell wall which gives enough strength and flexibility to the fibres [16]. The accumulation of minerals and simultaneous decrease in water potential associated with the final stage of fibre development, maturation/dehydration (45 to $50 \mathrm{dpa}$ ), resulting in a mature cotton fibre [13].

Cotton fiber development is regulated by a network of genes which are associated with the different metabolic pathways such as phytohormone signaling, energy metabolism of cell, fatty acid metabolism, secondary metabolism and other signaling pathways. However, the lack of enough information about the genes and regulatory components that regulate fiber development is one of the main constrain in understanding the genetics to improve cotton fiber quality. Phytohormones such as gibberlic acid [16], auxin [16, 17], ethylene [18] and transcription factors involved in SCW formation such as MYB-TFs [19] and lipid transfer proteins (LTPs) [20] of fatty acid metabolism and brassinosteroids (BR) $[16,21]$ participate in different stages of fibre development.
Mutants for particular traits are powerful resources for gene expression studies and mutant plants analysis has accelerated the finding and characterization of specific gene function. In the present study, comparative transcriptome analysis was performed in desi fuzzy-lintless $(F l)$ line and normal fuzzy linted $(F L)$ line at $0 \mathrm{dpa}$ and 10 dpa using Affymetrix cotton GeneChip genome array. Data from the present study indicates that transcription factors involved in SCW formation and the genes involved in phytohormone-mediated signaling pathways play a vital role in regulating fibre cell initiation and differentiation and the down-regulation of several genes involved in energy metabolism and fatty acid metabolism at $10 \mathrm{dpa}$ may be the probable reason for the reduced growth of fiber in the $F l$. Transcripts related to signaling i.e. $\mathrm{Ca}^{2+}$ and reactive oxygen species (ROS) as well as some heat shock proteins (HSPs) and spermine synthase (SPDS3) were down regulated mainly at 0 dpa lead to reduced fiber growth. This transcriptome analysis found specific genes which are playing role in the metabolic pathways of fibre development that might be useful for further comprehensive analysis of cotton fibre.

\section{Methods}

Plant materials for microarray and qRT-PCR experiments The near isogenic $F l$ (Fuzzy-lintless) line was generated by crossing $F L$ and $F l$ (recurrent parent) lines at Agriculture Research Station (Cotton), Dharwad Farm, UAS, Dharwad. Morphological trait parameters such as plant height, leaf shape, number of sympodia, number of fruiting bodies, flower colour, fibre length, etc. were observed in both fuzzy-linted $(F L)$ and fuzzy-lintless $(F l)$ line. Flowers were tagged with label on the day of anthesis and considered as $0 \mathrm{dpa}$ (days post anthesis). Samples were collected at 0 and $10 \mathrm{dpa}$ in liquid nitrogen and stored at $-70{ }^{\circ} \mathrm{C}$ until used for total RNA extraction. Samples were harvested and immediately frozen.

\section{Scanning electron microscopy}

Ovule samples were kept in tissue fixative consisting of $3 \%(v / v)$ glutaraldehyde in $0.1 \mathrm{M}$ sodium phosphate buffer and stored at $0-4{ }^{\circ} \mathrm{C}(2-4 \mathrm{~h})$ and then washed with $0.1 \mathrm{M}$ phosphate buffer $\mathrm{pH}=7.2(3 \times 10 \mathrm{~min})$. The samples were subjected for post-fixation in $1-2 \%$ osmium tetroxide $^{*}$ in $0.1 \mathrm{M}$ phosphate buffer** $\mathrm{pH}=7.2(2-4 \mathrm{~h})$ at room temperature and in a light tight container. Dehydration was carried out in a graded acetone series $30 \%$ $(\mathrm{v} / \mathrm{v}), 50 \%(\mathrm{v} / \mathrm{v}), 70 \%(\mathrm{v} / \mathrm{v})$, (stored tissue in $70 \%(\mathrm{v} / \mathrm{v})$ acetone for overnight), 80\% $(v / \mathrm{v}), 90 \%(v / \mathrm{v}), 96 \%(v / \mathrm{v})$, $100 \%(\mathrm{v} / \mathrm{v})$ for 5-15 min each and finally washed twice with $100 \%(v / v)$ ethanol (15-30 min each). Samples were mounted on stubs and allowed for metal coating with Gold- Palladium alloy. The SEM images were acquired 
by Zeiss EVO MA10 (Carl Zeiss, Oberkochen, Germany) at $15 \mathrm{kV}$ EHT. Number of fibre initials was quantified in $100 \mu \mathrm{m}^{2}$ area using ImageJ software.

\section{Composition}

* 1-2\% osmium tetroxide solution: $0.25 \mathrm{~g} \mathrm{OsO}_{4}$ $(1 \%)+25 \mathrm{ml} 0.1 \mathrm{M}$ phosphate buffer and washed with $0.1 \mathrm{M}$ phosphate buffer $\mathrm{pH}=7.2(3 \times 10 \mathrm{~min})$.

** $0.1 \mathrm{M}$ phosphate buffer: $15 \mathrm{ml}$ of sodium phosphate monobasic stock $(0.5 \mathrm{M})+60 \mathrm{ml}$ distilled water.

\section{Total RNA isolation}

Spectrum $^{\text {тм }}$ Plant Total RNA Kit (Sigma-Aldrich St. Louis, MO) was used to isolate total RNA from samples and column digestion was performed to overcome the problems of genomic DNA contamination. The concentration and quality of total RNA was checked by NanoDrop spectrophotometer (Thermo Scientific, USA) and agarose gel electrophoresis using $1.2 \%$ of agarose gel prepared in MOPS buffer. Samples were loaded and the gel electrophoresis was carried out at $70 \mathrm{v}$ for $20 \mathrm{~min}$ and checked under UV transilluminator by absorbance spectra at 260 and $280 \mathrm{~nm}$.

\section{Microarray hybridizations and data analysis}

The microarray utilized was the commercially available Affymetrix GeneChip ${ }^{\oplus}$ Genome array (Affymetrix Inc., Santa Clara, CA) having 23,977 probe sets representing 21,854 cotton transcripts from a variety of EST databases was used for transcriptome analysis. Three biological replicates were maintained to test the reproducibility and quality of the chip hybridization. Total RNA was isolated at $0 \mathrm{dpa}$ and $10 \mathrm{dpa}$ stage from $F L$ and $F l$ lines and used for preparation of cDNA GeneChip ${ }^{\circ}$ 3' IVT Express Kit. Array hybridization, staining and washing procedures were carried out according to the manufacturer's instructions.

Differentially expressed transcripts were analyzed with GeneSpring GX-11.5 software (Agilent Technologies, CA, USA). The Robust Multiarray Average (RMA) algorithm was used for normalization of the data in order to generate single expression value for each probe set. Normalized expression values were $\log _{2}$-transformed and unpaired t-test was performed for differential expression analysis. Differentially expressed transcripts (DETs) with false discovery rate (FDR) corrected $p$ value $\leq 0.01$ and fold change $\geq 3$ were included for further data analysis. DETs were classified using Cluster 3.0 hierarchical clustering software to profile the gene expression patterns during fibre development. To investigate the functional annotation of transcripts, the consensus sequences of probe sets present in the cotton GeneChip were mapped to the Arabidopsis TAIR protein database version 10 (http://www.arabidopsis.org/) by BLASTX with $E$ value cutoff $\leq \mathrm{e}^{-10}$. The DETs were also annotated based on NetAffx annotation data for cotton GeneChip (www.affymetrix.com/). Conserved sequences of all probe sets presented in cotton GeneChip were searched for putative transcription factors related to phytohormone biosynthesis and signal transduction pathways, against the Arabidopsis transcription factor database (http://plntfdb. bio.uni-potsdam.de, version 3.0) and Arabidopsis hormone database (http://ahd.cbi.pku.edu.cn, version 2.0) respectively, by BLASTX with $E$ value cutoff $\leq \mathrm{e}^{-10}$. Based on MIPS functional catalogue (https://www.helmholtz-muen chen.de/ibis/resourcesservices/genomics/funcat-the-func tional-catalogue/index.html) DETs were categorized into functional groups. Further, expressions of differentially regulated cotton transcripts were visualized onto metabolic pathways using MapMan software version 3.5.0 (http:// mapman.gabipd.org/ja/mapman-version-3.5.0/) [22]. The data generated in microarray analysis is deposited in the Gene Expression Omnibus database (GEO, http:// www.ncbi.nlm.nih.gov/geo) at the NCBI under the Series Accession number GSE52432.

\section{The quantitative real-time PCR (qRT-PCR) analysis}

On the basis of enrichment analysis of biological processes and expression profiles of genes differentially expressed during the initiation and elongation, 16 genes were selected for verification of the microarray data. cDNA was prepared with AffinityScript QPCR cDNA Synthesis Kit (Stratagene, Agilent Technologies, USA), following manufacturer protocol to make up a total reaction volume of $20 \mu \mathrm{L}$ using $1 \mu \mathrm{g}$ of total RNA. PrimerQuest software (http://eu.idtdna.com) was used for designing Gene specific qRT-PCR primer (Table 1). The qRT-PCR analysis was then carried out in triplates using a MX 3005P Real-Time PCR system (Stratagene, USA) equipped with a 96 well plates system with the SYBR green PCR Master mix reagent (Stratagene). The GhPP2A1 gene (Accession No: DT545658) from Gossypium hirsutum was used as reference gene to normalize the expression values [23].

\section{Results and discussion}

Morphology of fuzzy-lintless $(F I)$ and fuzzy-linted $(F L)$ line Morphological traits of $F l$ line were similar to that of Fuzzy-linted line $(F L)$ except for their fuzz and lint which represents less fuzz and normal lint (fibre length28-30 $\mathrm{mm}$ ) whereas, more fuzz and no any elongating fibers in fuzzy-lintless $(F l)$ line. There was no difference with respect to leaf colour, shape and hairiness. In both lines leaves were green, okra in shape and medium in hairiness. Stem was pigmented with medium hairiness. Both the genotypes possess medium round bolls and were pale green in colour with pointed nature. With respect to flower also, petal colour, anther colour and 


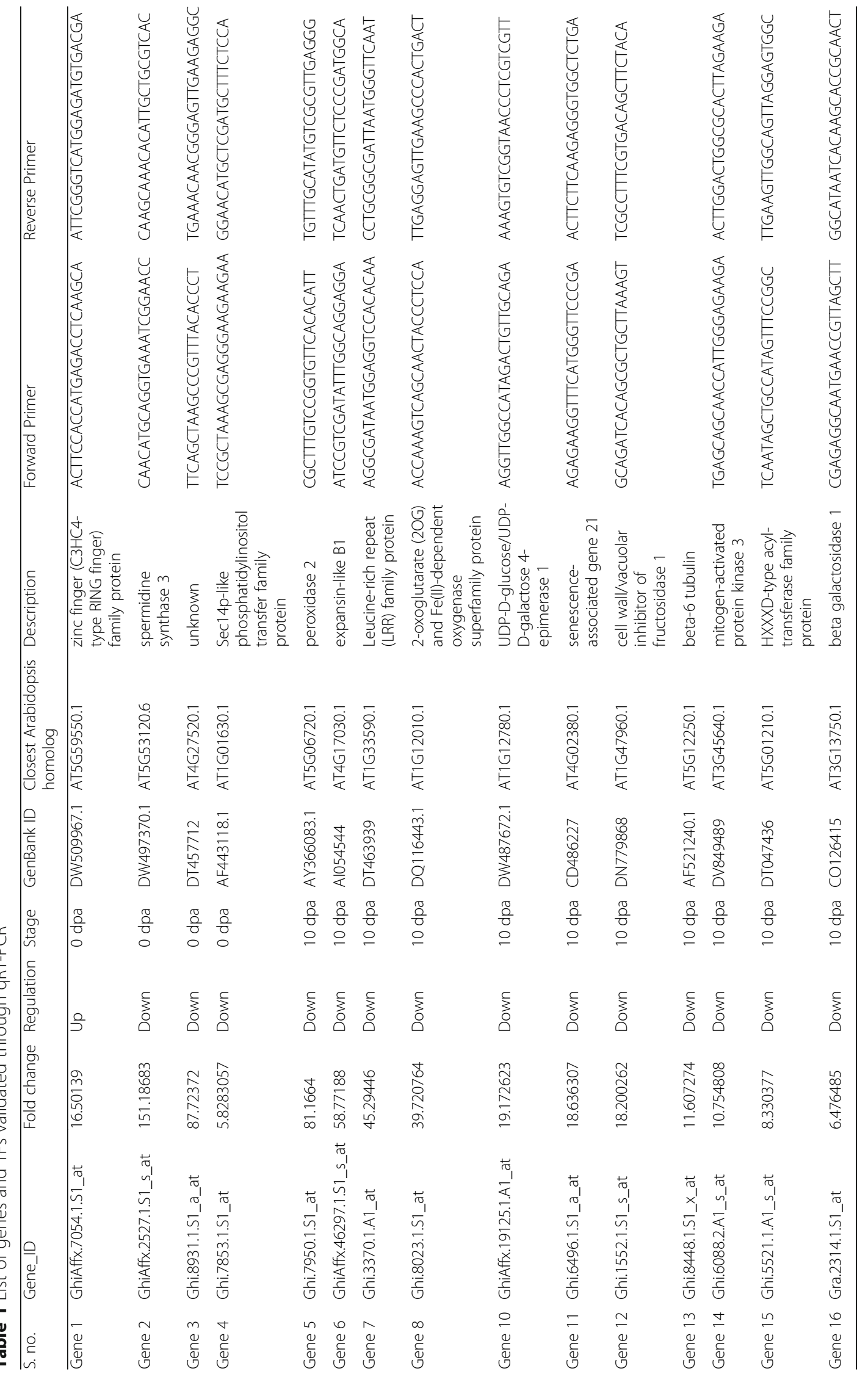


pollen colour was yellow, similarly anther filament colour was light yellow and normal sepal shape. The sympodial branching was alternative in both lines. Although they were not perfect isogenic lines, derived from $\mathrm{BC}_{1} \mathrm{~F}_{1}$.

Ovules of $F l$ line were compared with $F L$ line through SEM analysis to investigate the differences in early stages of fibre development and it revealed that the presence of very few fibre cell initials in the $F l$ line as compared to $F L$ line (Fig. 1). Fibre initials could be seen two days before anthesis ( $-2 \mathrm{dpa})$ as well as on the day of anthesis $(0 \mathrm{dpa})$ in the $F L$ line. But, the elongating fibre cells were distinctly observed only in fuzzy-linted $(F L)$ line represented in Fig. 1. This implicates the mutant gene functions in an early stage of fibre cell differentiation.

\section{Transcriptome and cluster analysis of differentially expressed transcripts}

To study the fibre development, a genome wide expression analysis was carried out at 0 and $10 \mathrm{dpa}$ using ovules of fuzzy-linted line $(F L)$ and fuzzy-lintless $(F l)$ line. Labeled RNA was hybridized to Affymetrix cotton GeneChip Genome array. After statistical analysis, transcripts with $p$ value $\leq 0.01$ and fold change $\geq 3.0$ were considered as differentially expressed in $F l$ line and the number of DETs identified at 0 and $10 \mathrm{dpa}$ in $\mathrm{Fl}$ line are compared with their respective stages in $F L$ line (Fig. 2a). Maximum number of transcripts (220, 79.14\% of total DETs) showed differential expression at $10 \mathrm{dpa}$ whereas, only few transcripts $(58,20.86 \%$ of total DETs) showed differential expression at 0 dpa. 8 DETs were found common in both 0 and $10 \mathrm{dpa}$ (Fig. 2b).

Further to profile the gene expression patterns during fibre development, 278 DETs were classified using hierarchical clustering software Cluster 3.0. The expression patterns were separated into six major clusters (A-F) based on tree branching (Fig. 2c). Transcripts expressed in $F l$ line as compared to normal line $(F L)$ during each stage within each cluster are presented as Cluster A representing 4 DETs commonly down regulated at $0 \mathrm{dpa}$ and $10 \mathrm{dpa}$; Cluster B represents 8 DETs down regulated at 0 dpa; Cluster $C$ represents 15 DETs up-regulated only at $10 \mathrm{dpa}$; Cluster D represents a maximum of 42 DETs up-regulated at $0 \mathrm{dpa}$; Cluster E represents 4 DETs up-regulated at 0 dpa but found down regulated at 10 dpa whereas, Cluster F depicts a maximum of 197 DETs down regulated at $10 \mathrm{dpa}$. These results indicate that differential expression of some genes between $F l$ and $F L$ may control fibre cell initiation and elongation. In the following studies, the key genes responsible for such difference between these lines are mentioned clearly.

\section{Annotation and functional classification of DETs}

DETs were annotated based on TAIR database (http:// www.arabidopsis.org). It was observed that out of 278 DETs, 239 (85.97\%) were matched with Arabidopsis

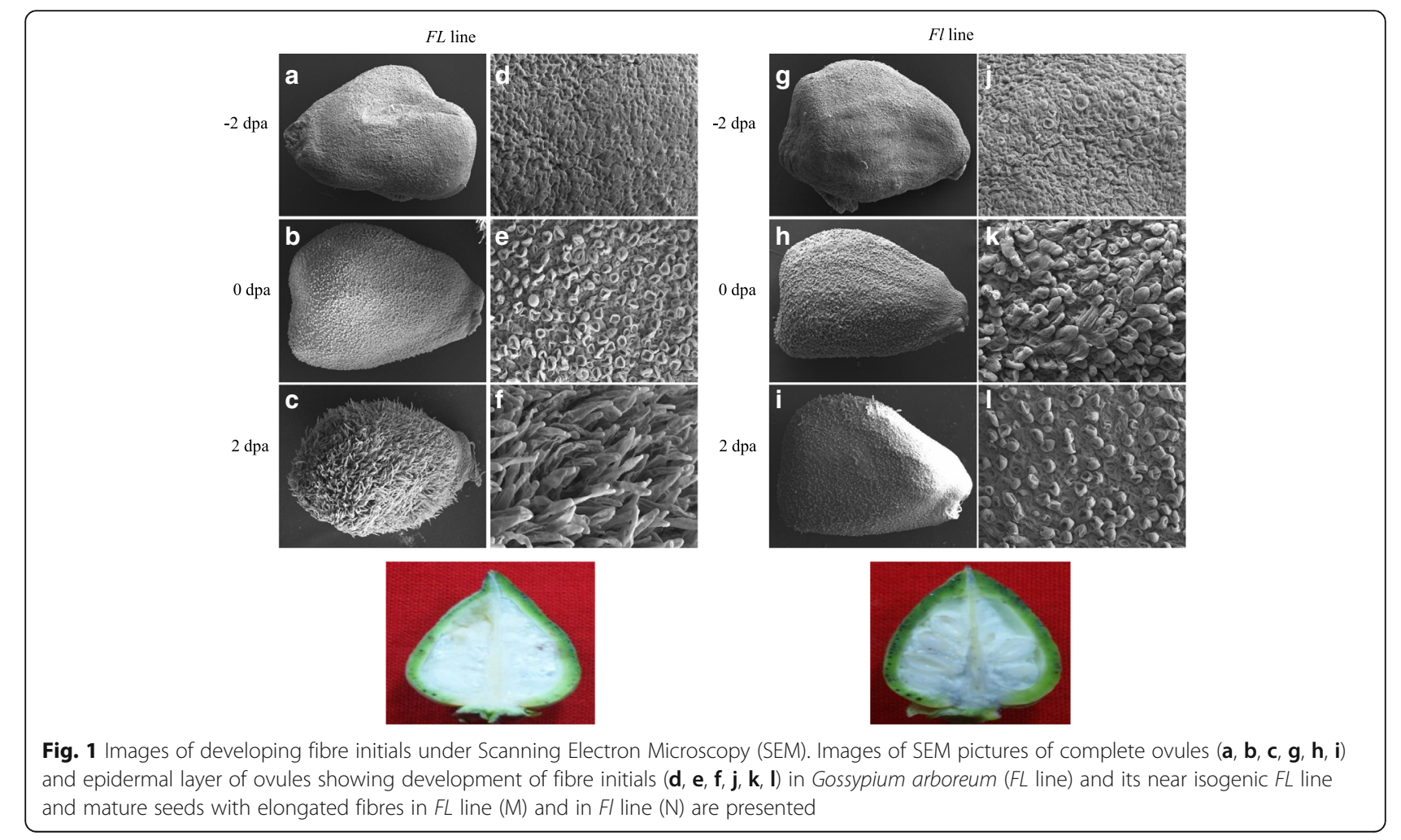




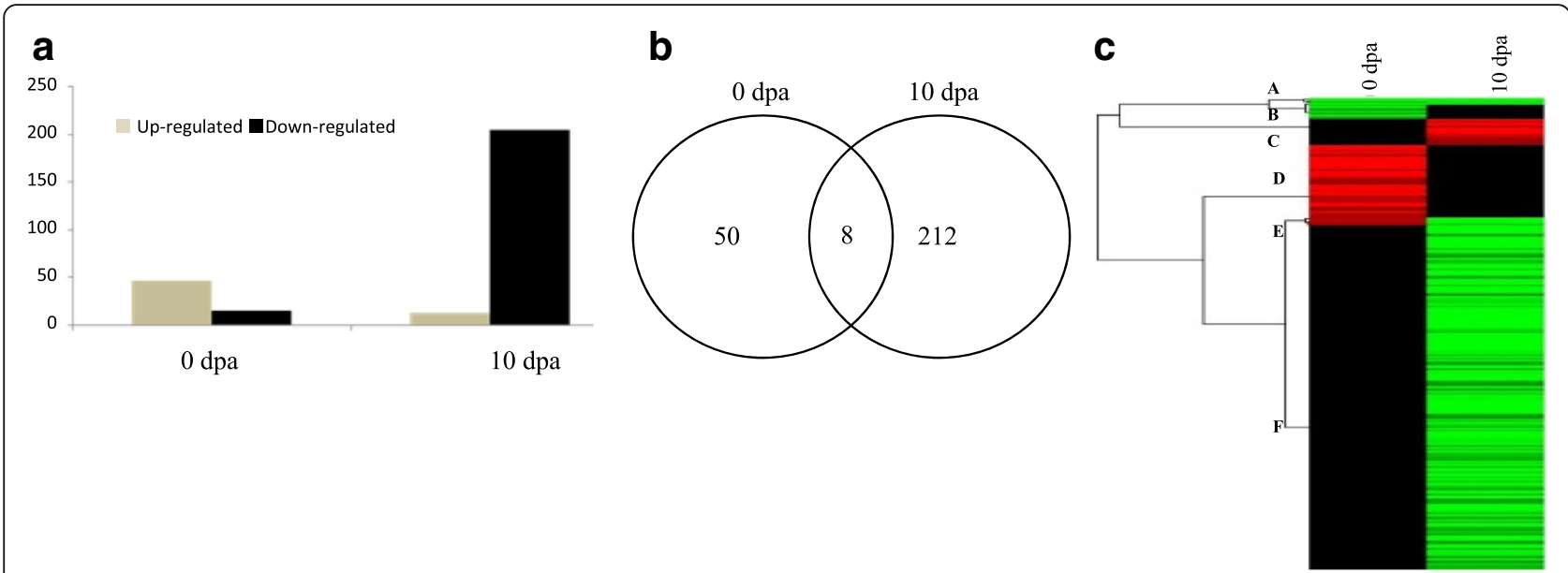

Fig. 2 Transcriptome analysis during fibre development stages normal fuzzy linted (FL) lines and fuzzy-lintless (FI) line. a Number of differentially expressed transcripts (DETs) in Fl line as compared to their respective stages in FL line at fibre initiation ( $0 \mathrm{dpa}$ ) and elongation (10 dpa) stages. b Venn diagram showing the commonly up- and down regulated transcripts between 0 and $10 \mathrm{dpa}$ stages in Fl line. c Hierarchical cluster analysis of differentially expressed transcripts (fold change $\geq 3$ ) in $F /$ line as compared to their respective stages in $F L$ line at 0 dpa $10 \mathrm{dpa}$. A to E indicates the five major clusters. Cluster A: Commonly down regulated transcripts at 0 and $10 \mathrm{dpa}$ in Fl line Cluster B: Only down regulated transcripts at 0 dpa in Fl line (8 DETs) Cluster C: Only up-regulated transcripts at $10 \mathrm{dpa}$ in F/ line (15 DETs) Cluster D: Only up-regulated transcripts at 0 dpa in Fl line (42 DETs) Cluster E: Up-regulated at $0 \mathrm{dpa}$ and down regulated at $10 \mathrm{dpa}$ in F/ line (4 DETs) Cluster F: Only down regulated transcripts at 10 dpa in Fl line (197 DETs)

gene models with $E$ value $\leq \mathrm{e}^{-10}$ (Additional files 1 and 2). Further, classification the DETs based on MIPS functional catalogue (https://www.helmholtz-muenchen.de/ ibis/resourcesservices/genomics/funcat-thefunctionalcatalogue/index.html) and DETs related to various transcription factor (TF) families were made into the different functional categories with respect to their putative functions. Phytohormone biosynthesis and signal transduction pathways were identified using Arabidopsis TF (http://plntfdb.bio.uni-potsdam.de/v3.0) and hormone (http://ahd.cbi.pku.edu.cn) databases, respectively (Fig. 3a; Additional files 3 and 4).

\section{Differentially expressed transcription factors}

In the present study, DETs encoding TF belonging to various families were identified in the $F l$ line in fibreinitiation and elongation stages as compared to $F L$ line. TFs belonging to AP2-EREBP, C2H2 and WRKY were highly up-regulated at fibre initiation (0 dpa). Similarly, transcripts encoding AP2-EREBP family TFs such as ethylene responsive element binding factors (ERFs), Integrase-type DNA-binding super family protein were highly down regulated at fibre elongation (10 dpa) stage in the $\mathrm{Fl}$ line. In addition, transcripts encoding salt tolerant zinc finger (STZ) TFs belonging to C2H2-type zinc finger family were down regulated at fibre initiation and elongation (Fig. 3a and Additional file 3). Further, transcripts (NAC047, NAC74, and NAC83) encoding NAC family were down regulated at $10 \mathrm{dpa}$ and WRKY family belonging to DNA binding protein and protein kinase family protein were also down regulated at elongation stage.

Other transcripts encoding AUX/IAA (indole-3-acetic acid), MYB domain, bHLH (basic helix-loop-helix), PLATZ (PLATZ transcription factor family protein), Orphans (Signal transduction histidine kinase, hybridtype, ethylene sensor), were down regulated at $10 \mathrm{dpa}$ (Fig. 5 and Additional file 3). Controlling the expression level of the gene by transcription factors is complex phenomenon which includes its binding to specific genomic sequences and promotes, enhance, or block transcription. Among the several identified TFs controlling fibre initiation, many families of plant TFs are involved in the stress induced signaling cascade. The TFs mainly including AP2-EREBP, WRKY, NAC, MYB and bZIP have been proved to play vital roles in the regulation [17, 24, 25]. In present study, TFs belonging to the AP2-EREBP, C2H2, and WRKY were highly upregulated at 0 dpa. Similarly, transcripts encoding AP2EREBP family TFs such as ethylene responsive ERFs, Integrase-type DNA-binding super family protein were highly down regulated at $10 \mathrm{dpa}$ in the $\mathrm{Fl}$ line. The AP2EREBP transcription factor takes part in hormone signaling [26], spikelet meristem determinacy [27], leaf epidermal cell identity [28], embryo development [29], and regulation of flower development positively [26, 30]. Kurek et al. [31] reported that Zinc finger (C3HC4-type) and NAC family transcription factors influences the SCW synthesis in Gossypium hirsutum fibre. Zinc finger (C3HC4-type) family TFs also regulates cellulose synthesis via oxidation of zinc-binding domains [31]. In present 


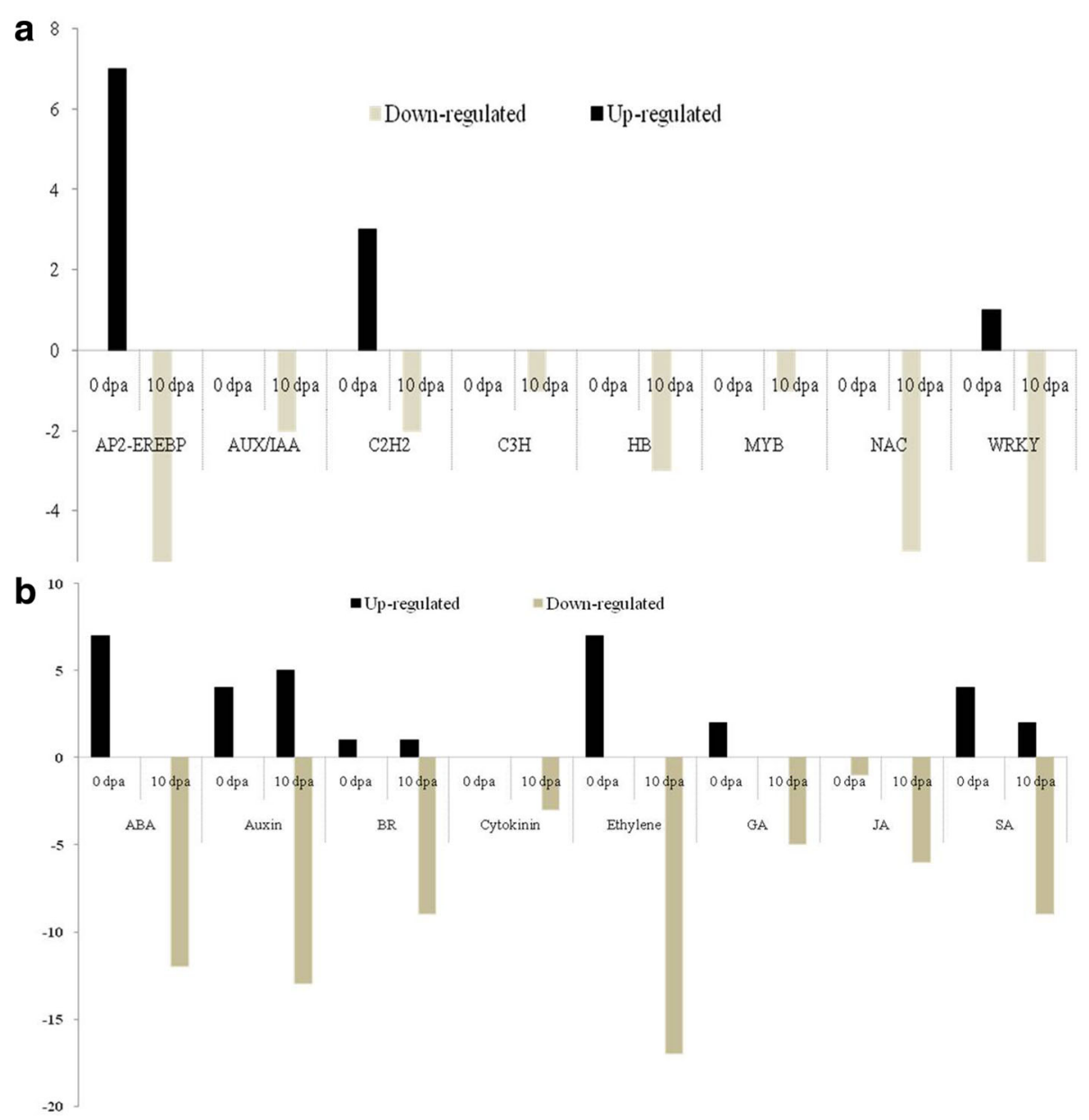

Fig. 3 Analysis of differently expressed transcripts (DETs) related to transcription factors (TFs) and phytohormone signaling (PHs) in F/ line compared to their respective stages in the FL line at fibre initation ( $0 \mathrm{dpa}$ ) and elongation (10 dpa) stages. a Number of DETs encoding TFs of various families in FL line at 0 and $10 \mathrm{dpa}$. b Number of DETs related to the phytohormone signaling in $F /$ line at 0 and $10 \mathrm{dpa}$

study, up-regulation of Zinc finger (C3HC4-type) at initiation stage reveals the probable role in preventing the fibre initiation in microarray analysis by 16.50139 folds and same is validated by qRT-PCR which was showing up-regulation by 3.33 fold change (Table 2 and Fig. 5 Gene 1).

\section{Phytohormones signaling}

Phytohormones are one of the important factors play critical role through intracellular signaling events leading to well-characterised changes in gene expression for regulating various plant growth and developmental processes. In the present investigation, DETs involved in phytohormone biosynthesis and signal transduction pathways were identified at different stages in fuzzylintless $F l$ line as compared to their respective stages in fuzzy-linted line $(F L)$. The genes involved in phytohormone signal transduction pathways and the biosynthesis of auxin, BR, ethylene, gibberellic acid (GA) and salicylic acid (SA) were found to be up-regulated at fibre initiation in the $F l$ line. But a single transcript encoding the jasmonic acid (JA) coding allene oxide synthase was found to be down regulated (Fig. 3b and Additional file 4). During the fibre elongation stages, transcripts which were found to be up-regulated at initiation were down regulated. Previous investigations reported that ethylene [18], auxin [16, 17], BR [16, 21], SA [16], GA [16], having additive effect on early fibre development and elongation.

High level of iaaM transcript was recorded in ovules of the transgenic lines transformed with epidermis cell specific promoter FBP7 relative to wild type on the day of flowering (0 dpa) [16]. More number of fibre initials and elongating fibres at 0 to $3 \mathrm{dpa}$ and significantly higher level of bioactive Gibberellic Acid (GA) in 0 dpa ovules and $10 \mathrm{dpa}$ fibres due to constitutive over-expression of GhGA20ox1 in cotton [32]. In the present investigation number of genes involved in phytohormone biosynthesis and signal transduction pathways were unraveled, changes 


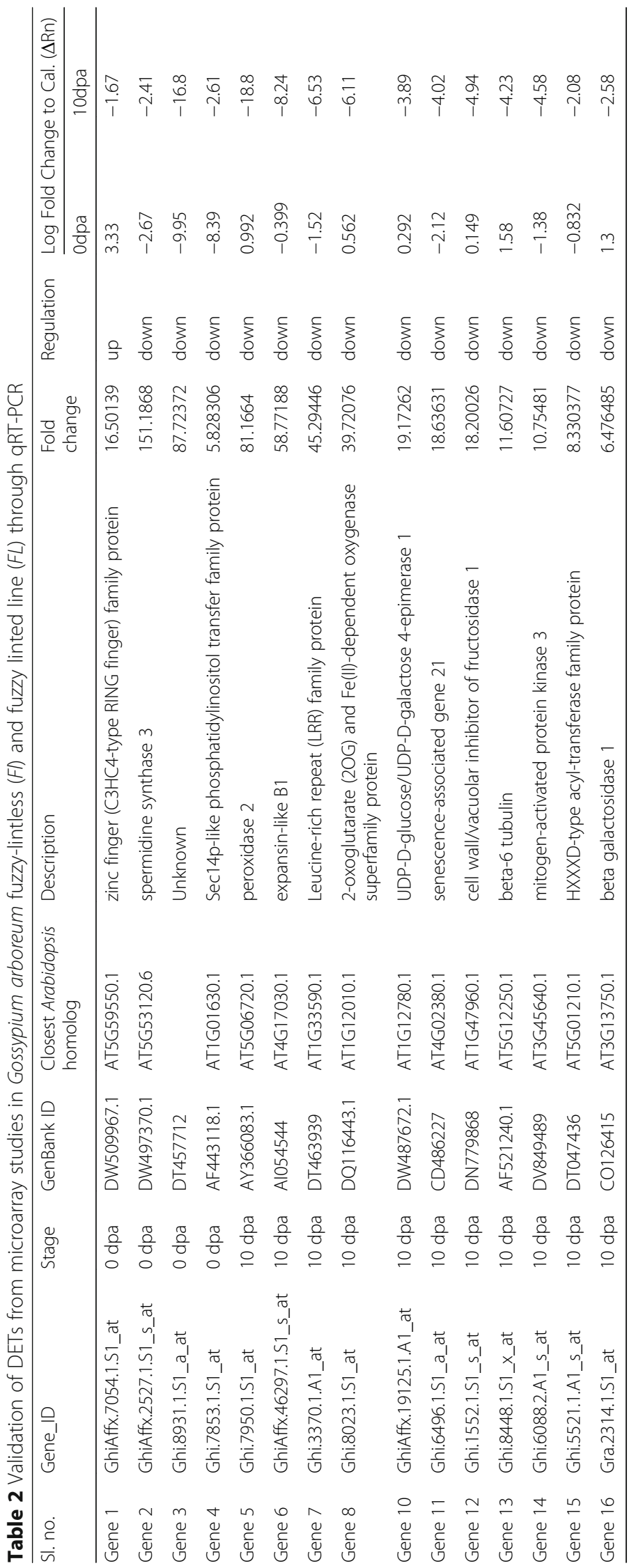


in their expression level at different stages of the fiber development supports their role in fiber initiation and elongation. Sun et al. [33] collected the cotton ovules, on the day of anthesis and treated with brassinolide (BL) and brassinazole2001 (Brz) inhibitor. Fibre elongation was suppressed in the ovules treated with Brz while it was enormously increased in case of BL treatment, shows positive correlation between BR-regulated gene expression and fiber elongation [33].

\section{Different pathways expressed during the developmental stages}

Mapman software version 3.5.0 (http://gabi.rzpd.de/projects/MapMan/) visualization shows overview of different metabolic pathways of the DETs involved in the $F l$ line at $0 \mathrm{dpa}$ and $10 \mathrm{dpa}$ (Additional files 5 and 6), respectively. Small blue and red colour squares indicate up- and down regulated transcripts, respectively (Fig. 4). This overview provides insight into specific functions, e.g. cell wall structure, metabolism, cell fate, signaling pathways etc. Some of the DETs are short listed (Additional files 7 and 8) which are present in various metabolic pathways in Gossypium arboreum fuzzy-lintless line $(F l)$ at 0 and $10 \mathrm{dpa}$.

\section{Energy and cell wall metabolism}

During the initiation stage, there was no any expression/ up-regulation of transcript encoding the carbohydrate (CHO) metabolism. But at the elongation stage, certain DETs encoding the minor $\mathrm{CHO}$ metabolism were down regulated. Transcripts encoding the enzymes involved in $\mathrm{CHO}$ metabolism and cell wall metabolism included Haloacid dehalogenase-like hydrolase (HAD) superfamily protein and also the enzymes involved in trehalose biosynthesis such as trehalose-phosphate phosphatase 9 (TPP) were down regulated at fibre elongation stage (Additional file 6). Recently, similar results have been found in the fuzzless-lintless mutant of Gossypium hirsutum L. cv.MCU5. Trehalose 6- phosphate synthase (TPS) were highly down regulated at fibre elongation stage indicating the role of these genes in fibre development and stress adaptation [8].

In fibre cells, cell wall biosynthesis is a major synthetic activity. Several transcripts take part in primary and secondary cell wall biosynthesis were differentially expressed at different stages of fibre development in fuzzy-lintless $(F l)$ line as compared to their respective stages in fuzzy-linted line $(F L)$ (Fig. 4, Additional files 5 and 6). A number of genes involved in primary cell wall biosynthesis and elongation such as those coding for xyloglucanases, peptidoglycan-binding, expansins and glucose/galactose epimerase were down regulated at 10 dpa. UDP-D glucose (UDP-Glc) acts as a prime metabolite in carbohydrate metabolism, and also the precursor for the synthesis of cell wall polysaccharides such as pectin, hemicelluloses, and cellulose. In the present study, transcripts encoding the enzymes involved in synthesis of cell wall precursors, such as UDP-D-Glc/UDP$\mathrm{D}$-galactose 4-epimerase 1 were down regulated during fibre elongation stage in the $\mathrm{Fl}$ line confirmed by microarray analysis (19.17262 folds) and was also validated by qRT-PCR (3.89 folds) (Table 2 and Fig. 5, Gene 10). Some DETs coding for enzymes like UDP glucosyl and glucoronyl transferases family involving UDP-glucosyl transferase 74B1 (UGT74B1) and UDP-glucosyl transferase $74 \mathrm{C1}$ (UGT74C1) and galactosidases (GAL) like $\beta$-galactosidase 1 and $\beta$-galactosidase 2 were highly down regulated at $10 \mathrm{dpa}$ in the $F l$ line which is one of the convincing reasons for proving their role in fibre development.

In the present study at $0 \mathrm{dpa}$, transcripts encoding for cell wall modification like xyloglucan endotransglucosylase/hydrolase family protein (XTHs) and EXPANSINS were up-regulated. Transcripts encoding endo-xyloglucan hydrolase/XTH7 and endo-xyloglucan hydrolase/XTH32 involved in fibre elongation were highly up-regulated at 0 and $10 \mathrm{dpa}$ that is the possible reason in the fuzz development. Fasciclin-like domain of AGPs, are important for cell-to-cell communication during cotton fibre elongation and secondary cell wall development [34] were also highly up-regulated. Further, transcripts encoding actin binding proteins such as profilin 5 (PRF5), actins (ACTs) which was actin depolymerizing factor 5 , and $\beta$-tubulins coding for beta- 6 tubulin were down regulated at $10 \mathrm{dpa}$ involved in cell wall elongation and loosening, structural reinforcement and cytoskeleton dynamics indicating their role in fibre development. Pectin modifying enzymes such as pectin methylesterase inhibitor family protein coding for cell wall/vacuolar inhibitor of fructosidase 1 was down regulated during the elongation stage. Pectins are major components of the primary cell wall forms $25 \%$ of the cell wall constitution in cotton fibre. Thus, pectin modifying enzymes play a major role in the fibre cell wall development.

\section{Fatty acid (FA) metabolism}

Fatty acid metabolism is responsible for the biosynthesis of many cellular lipids especially membrane components, hence rapid fatty acid synthesis in an elongating cotton fibre is expected. In the present study, no transcript encoding the enzymes involved in the biosynthesis of fatty acids was found at 0 dpa but seven acyl-activating enzymes involved in the FA synthesis and elongation were found to be down regulated in $F l$ line. The transcripts encoding alpha/beta-hydrolases protein which are essential for the lipid metabolism and lipid degradation were also found down regulated during the elongation phase. In addition, the factor acyl-CoA oxidase 4 essential for lipid 


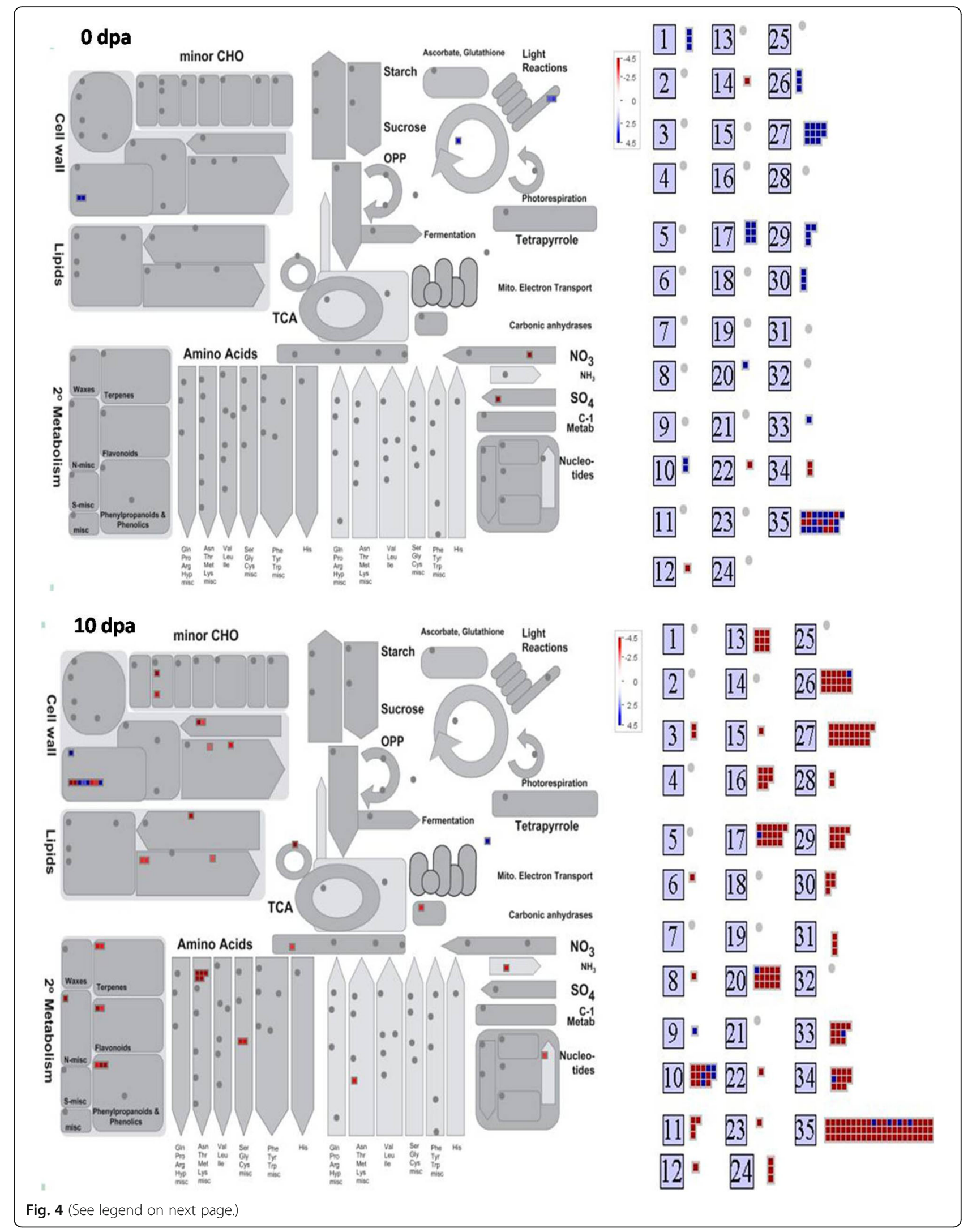


(See figure on previous page.)

Fig. 4 Overview of differentially expressed transcripts present in various metabolic processes based on MapMan (version 3.5) visualization software in FL line at $0 \mathrm{dpa}$ and $10 \mathrm{dpa}$ 1: PS (Photo System), 2: Major CHO metabolism, 3: Minor CHO metabolism, 4: Glycolysis, 5: Fermentation, 6: Gluconeogensis/glycoxylate cycle, 7: OPP (O-phenylphenol), 8: TCA (tricarboxylic acid)/Org. transformation, 9: Mitochondrial electron transport/ ATP synthesis, 10: Cell wall, 11: Lipid metabolism, 12: N-metabolism, 13: Amino acid metabolism, 14: S-assimilation, 15: Amino acid metabolism, 16: S-assimilation, 17: Hormone metabolism, 18: Co-factor and vitamine metabolism, 19: Tetrapyrrole synthesis, 20: Stress, 21: Redox, 22: Polyamine metabolism, 23: Nucletotide metabolism, 24: Biodegradation of Xenobiotics, 25: C1-metabolism, 26: Misc27: RNA, 28: DNA, 29: Protein, 29: Protein, 30: Signalling, 31: Cell, 32: Micro RNA, Natural antisense etc., 33: Development, 34: Transport, 35: Not assigned

metabolism and degradation involved in the beta-oxidation of the FA was also down regulated at $10 \mathrm{dpa}$ (Additional file 6). Fatty acids (phosphoinositol and sphingolipids, and VLCFA-very-long-chain fatty acids) are the signaling molecules play crucial role in the fibre elongation. It was found that VLCFA accumulated more in elongating fibres as compared to ovules and the cotton genes involved in VLCFA biosynthesis (ketoacyl-coa synthase - KCS12, KCS6, KCS13, and KCS2) were up-regulated [35]. In the present study, there were hardly any transcript found encoding the enzymes involved in the biosynthesis of fatty acids at 0 dpa but transcripts involved in the FA synthesis at $10 \mathrm{dpa}$ were found to be down regulated. The transcripts encoding alpha/beta-hydrolases protein which are essential for the lipid metabolism and lipid degradation were also found down regulated during the elongation phase. In addition, the factor acyl-CoA (ACO) oxidase 4 essential for lipid metabolism and degradation involved in the beta- oxidation of FA was down regulated at $10 \mathrm{dpa}$. Saturated VLCFAs may promote cotton fibre and Arabidopsis cell elongation by activating ethylene biosynthesis gene ACOs [35], pointing out an important link between the VLCFA biosynthesis and cotton fibre elongation. Studies in both Arabidopsis and cotton indicated that VLCFAs are involved in regulation of fibre elongation through their interplay with auxin and ethylene with subsequent stimulation of fibre cell elongation [35, 36].

LTPs are involved in transport of lipids from endoplasmic reticulum (ER) to plasma membrane (PM), where it acts as immediate acceptors of cuticular lipids from the plant ABCG transporters. Of course, this activation model would require either the shuttling of LTPs from the surface of the PM to cell wall [20,37]. In the present study, bifunctional inhibitor/lipid-transfer protein also known seed storage $2 \mathrm{~S}$ albumin super family protein and Sec14p-like phosphatidylinositol transfer family protein

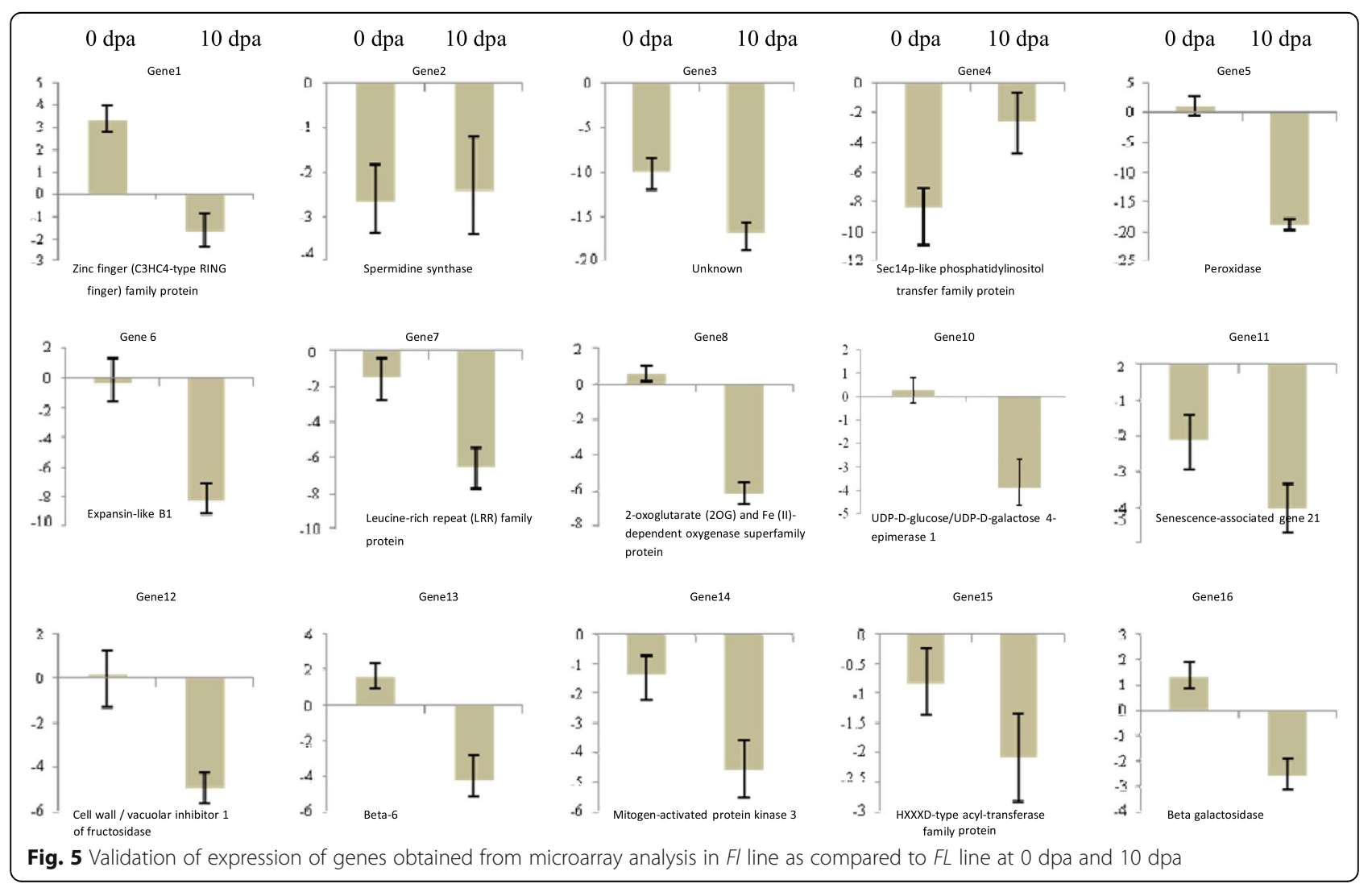


(PITP) were down regulated at 0 dpa in microarray by 5.828306 folds and also validated using qPCR showing its down-regulation by 8.39 folds which suggest the formation of fuzz in the $F l$ line (Table 2 and Fig. 5, Gene 4). Transcripts encoding the cell wall/vacuolar inhibitor of fructosidase-1 (C/VIF, cell wall/vacuolar inhibitor of fructosidase) having role in the carbohydrate metabolism and sugar signaling and related to pectin metabolism was found to be down regulated at $10 \mathrm{dpa}$ (Additional file 6).

\section{Secondary metabolism}

Secondary metabolism and modification of genes are amongst the most statistically significant differentially expressed categories during fibre elongation. In present study, not a single transcript was preferentially expressed at fibre initiation stage but during elongation stage, numbers of genes involved in secondary metabolism were down regulated. This included genes for many of enzymes of the isoprenoids, carotenoids and terpenoids coding beta ring hydroxylase 2 and terpene synthase 21 respectively. Gibberellin 3-oxidase 1 involved in synthesis of flavonols was also down regulated. Enzymes responsible for the synthesis of phenyl propanoid and lignin includes nicotinamidase 1, HXXXD-type acyl-transferase family protein, caffeoyl-CoA 3-O-methyltransferase were also down regulated. To date, only three genes of BAHD family of HXXXD-type acyltransferases which are mainly involved in alkyl hydroxyl cinnamate ester synthesis have been identified [38, 39]. Formation of feruloyloxy aliphatics (i.e. ferulate linked to the $\omega$-terminus of $\omega$ hydroxy fatty acids) in suberin and cutin polymers is the primary function of these genes. In Arabidopsis thaliana, alkyl ferulates comprise only a small proportion of the alkyl hydroxyl cinnamate esters extracted from roots [40]. Limited efforts on physiological parameters of roots that might be attributed to alkyl hydroxycinnamates and the general lack of information on mature Arabidopsis roots (transcriptome, stress experiments, etc.) provoked the researchers to induce the production of root alkyl hydroxycinnamate, alkyl coumarates and caffeates, that forms the components of Arabidopsis thaliana root waxes present primarily in taproots. Incorporation of ferulate into aliphatic suberin in Arabidopsis mediated by Aliphatic suberin feruloyl transferase (At5g41040) is a HXXXDtype acyltransferase (BAHD family). However, alkyl hydroxycinnamate ester root wax composition does not affect the aliphatic suberin feruloyl transferase mutants [41]. Here transcript coding HXXXD-type acyl-transferase was down regulated in microarray by 8.330377 and its validation suggesting down-regulation by 2.08 folds in $F l$ line which may lead to the formation of the secondary metabolites and reduced growth of the elongating fibres (Additional files 5 and 6; Table 2 and Fig. 5, Gene 15). Same kind of results has been reported by Tan et al., [42] that naringenin (NAR) a substrate of flavanone 3hydroxylase $(\mathrm{F} 3 \mathrm{H})$ gene and silencing the $\mathrm{F} 3 \mathrm{H}$ gene could significantly retard fiber development [42]. F3H mediated metabolism was evident from the results of Negative association of NAR with fiber development, thus indicating importance of flavonoid metabolism as a novel pathway with the potential for cotton fiber improvement.

\section{Transcripts related to signaling}

Transcript coding signaling molecules such as calcium $\left(\mathrm{Ca}^{2+}\right)$ and ROS specifically superoxide $\left(\mathrm{O}_{2}^{-}\right)$and hydrogen peroxide $\left(\mathrm{H}_{2} \mathrm{O}_{2}\right)$ have been studied recently for their role in cotton fibre development. In the present study, calcium signaling molecules associated with transcripts encoding Calcium-binding EF-hand family protein and ATPase E1E2 type family protein/haloacid dehalogenase-like hydrolase family protein were up-regulated during initiation stage in $F l$ line as compared to $F L$ line (Additional files 5 and 7). Transcripts involved in ROS including peroxidase superfamily Peroxidase 2 protein were down regulated at the elongation stage in this line (Additional files 6 and 8). These results showed the correlation with the previous studies indicates that ROS induced by exogenous $\mathrm{H}_{2} \mathrm{O}_{2}$ and $\mathrm{Ca}^{2+}$ starvation promotes early fiber elongation. Fiber cells show increased ROS concentrations compared with the wild-type due to GhCaM7 overexpression, while GhCaM7 RNAi fiber cells have reduced concentrations. Furthermore, $\mathrm{H}_{2} \mathrm{O}_{2}$ enhances $\mathrm{Ca}^{2+}$ influx into the fiber and intern-regulates the expression of GhCaM7. Increase in the cellular concentration of reactive oxygen species (ROS), subsequently converted to hydrogen peroxide $\left(\mathrm{H}_{2} \mathrm{O}_{2}\right)$. Biotic and/or abiotic stress causes an oxidative burst creating disturbance in the cellular redox balance. This redox modulation could potentially alter protein conformation, affecting protein activity, and therefore initiating subsequent cellular responses is highly toxic to cells. In addition to being a toxicant, it has been considered as a signaling molecule and a regulator of the expression of some genes viz., genes encoding antioxidants, cell rescue/ defense proteins, and signaling proteins such as kinase, phosphatase, and transcription factors [43].

In cotton, ROS was detected through fluorescence of the ROS indicator 2', 7'-dichlorodihydrofluoroscein diacetate (2, 7-DCH2FDA) in fiber initials at $0 \mathrm{dpa}$ [44]. When bolls of Gossypium hirsutum fiber initiation mutants, naked seed (N1) and fuzzless Xinxianxiaoji (XinFLM), were treated with $\mathrm{H}_{2} \mathrm{O}_{2}$, fiber initials were expressed in both mutants by 0 dpa [45] indicating the role for ROS in fiber initiation. Similarly, research has begun to describe how $\mathrm{Ca}^{2+}$ participates in cotton fiber initiation and elongation [46] and it was observed that $\mathrm{Ca}^{2+}$ accumulation was correlated with fiber initiation 
and ER development in 0 dpa ovules compared to -1 dpa ovules, inline to this Microarray analysis showed that genes encoding components (calmodulin binding protein) of $\mathrm{Ca}^{2+}$ signaling were up-regulated at $1 \mathrm{dpa}$ [25].

In plants, protein kinases and phosphatases play a key role in biotic and abiotic stress responses with concern in a wide range of developmental processes. In the present study several classes of protein kinases were found to be differentially expressed at MAPKs namely MPK3 and MPK9 were down regulated during 10 dpa. Similarly, receptor kinases like LLR transmembrane protein kinase and polygalacturonase inhibiting protein 1 belonging to LLR family were also shown down-regulation (Additional files 6 and 8).

\section{Other metabolisms}

In the present study, down-regulation of certain transcripts like HSP20-like chaperones superfamily protein codes for HSPs, LRR family protein and senescence related genes/proteins coding for senescence-associated gene 21 which have been in association to the stresses. Transcript associated with the abiotic stress coding for Chaperone DnaJ-domain superfamily protein was found to be up-regulated at fibre initiation stage and the same was showing down-regulation at elongation stage. While studying the $F l$ line, spermidine protein encoding spermidine synthase was showing up-regulation at $0 \mathrm{dpa}$ and down-regulation at $10 \mathrm{dpa}$ (Additional files 5 and 6). All these factors support to abiotic stress resistance in plants. Therefore, their down-regulation arrested fibre elongation (as fibre elongation itself is a stressful process).

\section{Quantitative reverse transcription PCR}

A total of 16 genes were selected for verification of the microarray data based on enrichment analysis of biological processes and expression profiles of genes differentially expressed during the initiation and elongation. (Table 2 and Fig. 5).

Several key gene function categories were selected which included cell wall biosynthesis and elongation factors including EXPANSIN-like B1, UDP-D-glucose/ UDP-D-galactose 4-epimerase 1 , tubulins, $\beta$-galactosidases, transcription factor like Zinc finger (C3HC4-type RING finger) family protein, MYB domains, LTPs like PITP, KCS genes involved in cellular communication and signal transduction encoding MAPK, MPKs.

For validation the cytoskeleton related genes having role in fibre elongation and onset of secondary cell wall deposition like actin depolymerizing factor (ADFs) were also selected. Genes like senescence-associated gene/ SAG21 which responds to dehydration and signal transduction related genes like calcineurin b-like protein 01 (CBL1) involving in the calcium signaling. Some genes involved in carbohydrate metabolism, stress responses and sugar signaling like cell wall/vacuolar inhibitor of fructosidase 1 (AtC/VIF, cell wall/vacuolar inhibitor of fructosidase) and LRR proteins and Peroxidase 2 involving in ROS scavenging were also validated using qRT-PCR. The fold change regulation and the results are represented in the Table 2 and Fig. 5.

\section{Conclusion}

Phenotypic characterization of fuzzy-lintless $(F l)$ line provides the information in elucidating mechanism regulating cotton fiber development and morphological difference between the lines. SEM analysis showed no difference in the fibre initials except for the fuzz development in fuzzy-lintless $(F l)$ line which is due to the downregulation of some genes necessary for fibre development. Up-regulation of the transcription factors like AP2EREBP, C2H2, C3H, HB, WRKY and phytohormones (auxin, ethylene, gibberlic acid and BR) biosynthesis at 0 dpa and their down-regulation at the $10 \mathrm{dpa}$ might loss the co-ordination in the development process and ceased the fibre growth in fuzzy-lintless line. Likewise, genes involved in synthesis of VLCFA chain, singaling molecules in lipid metabolism (PtdIns) get down-regulated. Downregulation of the transcripts necessary for the energy and cell wall metabolism such as TPS, endo-xyloglucan hydrolase family proteins, UDP-glucose 4-epimerase (UGE), EXPANSINs, AGPs and tubulin may be the probable reason for the undergrowth of the fibre in the $F l$ line. Transcript related to signaling i.e. $\mathrm{Ca}^{2+}$ and $\mathrm{ROS}$ as well as some HSPs and SPDS3 was down regulated mainly at 0 dpa which may lead to reduced fiber growth. Some miscellaneous factors like cellular and signal transduction coding for MAPK cascade, plant RLKs and LRR family proteins were down regulated at $10 \mathrm{dpa}$. Down-regulation of such of these factors known for cellular communication during fibre development resulted into fibrelessness in the mutant $F l$ line. This report also supports the previous findings of role of phytohormones in fibre development and LTPs in the transport of lipid molecule from plasma membrane to the cell wall.

\section{Additional files}

Additional file 1: Table S1. Differentially expressed transcripts in Gossypium arboreum fuzzy-lintless line (FI) as compared to fuzzy-linted line ( $F L)$ at fibre initiation stage (0 dpa). (DOC $93 \mathrm{~kb}$ )

Additional file 2: Table S2. Differentially expressed transcripts in Gossypium arboreum fuzzy-lintless line (FI) as compared to fuzzy-linted line (FL) at fibre initiation stage (10 dpa). (DOC $284 \mathrm{~kb}$ )

Additional file 3: Table S3. Differentially expressed transcripts encoding transcription factors (TFs) in Gossypium arboreum fuzzy-lintless line $(F I)$ as compared to fuzzy-linted $(F L)$ at fibre itiation stage (0 dpa) and fibre elongation stage (10 dpa). (DOC $75 \mathrm{~kb}$ ) 
Additional file 4: Table S4. Differentially expressed transcripts related to phytohormone signalling in Gossypium arboreum fuzzy-lintless line (FI) as compared to fuzzy-linted (FL) at fibre at $0 \mathrm{dpa}$ and $10 \mathrm{dpa}$. (DOC $156 \mathrm{~kb}$ )

Additional file 5: Table S5. Overview of differentially expressed transcripts present in various metabolic processes based on MapMan (version 3.5) visualization software Gossypium arboreum fuzzy-lintless line (FI) at $0 \mathrm{dpa}$ (DOC $103 \mathrm{~kb}$ )

Additional file 6: Table S6. Overview of differentially expressed transcripts present in various metabolic processes based on MapMan (version 3.5) visualization software in Gossypium arboreum fuzzy-lintless line (FI) at $10 \mathrm{dpa}$. (DOC $313 \mathrm{~kb}$ )

Additional file 7: Table S7. Short listed view of differentially expressed transcripts present in various metabolic processes based on MapMan (version 3.5) visualization software in Gossypium arboreum fuzzy-lintless line (FI) at $0 \mathrm{dpa}$. (DOC $37 \mathrm{~kb}$ )

Additional file 8: Table S8. Short listed view of differentially expressed transcripts present in various metabolic processes based on MapMan (version 3.5) visualization software in Gossypium arboreum fuzzy-lintless line (FI) at $10 \mathrm{dpa}$. (DOC $93 \mathrm{~kb})$

\section{Abbreviations}

2, 7-DCH2FDA: 2', 7'-dichlorodihydrofluoroscein diacetate; ACO: Acyl-CoA: ACTs: Actins; ADFs: Actin depolymerizing factor; AGPs: Arabinogalactan proteins; BL: Brassinolide; BR: Brassinosteroids; CBL1: Calcineurin b-like protein 01; DETs: Differentially expressed transcripts; DPA: Days post anthesis; ER: Endoplasmic reticulum; ERFs: Element binding factors; F3H: Flavanone 3-hydroxylase; FDR: False discovery rate; GA: Gibberellic acid; GAL: Galactosidases; $\mathrm{H}_{2} \mathrm{O}_{2}$ : Hydrogen peroxide; HAD: Haloacid dehalogenase-like hydrolase; HSPs: Heat shock proteins; JA: Jasmonic acid LTPs: Lipid transfer proteins; NAR: Naringenin; PITP: Phosphatidylinosito transfer family protein; PM: Plasma membrane: RLKs: Plant receptor-like kinases; RMA: Robust Multiarray Average; ROS: Reactive oxygen species; SA: Salicylic acid; SCW: Secondary cell wall; SCWD: Secondary cell wall deposition; SEM: Scanning electron microscopy; SPDS3: Spermine synthase; STZ: Salt tolerant zinc finger; TF: Transcription factor; TPP: Trehalosephosphate phosphatase 9; TPS: Trehalose 6- phosphate synthase; UDPGlc: UDP-D glucose; UGT74B1: UDP-glucosyl transferase 74B1; UGT74C1: UDP-glucosyl transferase 74C1; VLCFA: Very-long-chain fatty acids; XTHs: Xyloglucan endotransglucosylase/hydrolase family protein

\section{Acknowledgements}

The authors would like to thank Indian Council of Agricultural Research (ICAR) for extending support to carry out the research work under National Agricultural Innovation Project (NAIP).

\section{Authors' contribution}

ASH, ISK, MPJ, SG and SA performed all phenotypic evaluations, data analysis and manuscript preparation. ASH, KVP, GD and MK conducted microarray experiments and analyzed the transcriptome data. VSR and PAK involved in the designing of the experiments, data analysis, manuscript preparation and discussion. All authors read and approved the manuscript.

\section{Funding}

Indian Council of Agricultural Research (ICAR) - National Agricultural

Innovation Project (NAIP) supported for complete research work.

\section{Availability of data and materials}

Data supporting the findings is contained within the manuscript.

\section{Ethics approval and consent to participate}

Not applicable.

\section{Consent for publication}

Not applicable.

\section{Competing interests}

The authors declare that they have no competing interests.

\section{Publisher's Note}

Springer Nature remains neutral with regard to jurisdictional claims in published maps and institutional affiliations.

\section{Author details}

${ }^{1}$ University of Agricultural Sciences, Dharwad, Karnataka, India. ${ }^{2}$ National Research Centre on Plant Biotechnology (NRCPB), IARI, New Delhi, India. ${ }^{3}$ Plant Transformation Group, International Centre for Genetic Engineering \& Biotechnology (ICGEB), New Delhi, India.

Received: 4 September 2016 Accepted: 16 August 2017 Published online: 31 August 2017

\section{References}

1. Farooq J, Farooq A, Rizwan M, Petrescu-Mag IV, Ali MA, Mahmood K, Batool A. Cotton fibers: attributes of specialized cells and factors affecting them. AES Bioflux. 2015;7(3):369-82.

2. Zhang HB, Li Y, Wang B, Chee PW. Recent advances in cotton genomics. Int J Plant Genomics. 2008;2008:742304. doi:10.1155/2008/742304.

3. Wendel JF, Brubaker CL, Percival AE. Genetic diversity in Gossypium hirsutum and the origin of upland cotton. Am J Bot. 1992;79:1291-310.

4. Lee JJ, Woodward AW, Chen ZJ. Gene expression changes and early events in cotton fibre development. Ann Bot. 2007;100(7):1391-401.

5. Fan L, Hu W, Yang Y, Li B. Plant Special Cell - Cotton Fiber. Dr. John Mworia editors. Botany. InTech, Janeza Trdine 9, 51000 Rijeka, Croatia: 2012. p. 211-226.

6. Wilkins TA, Arpat AB. The cotton fiber transcriptome. Physiol Plant. 2005:124(3):295-300.

7. Kim HJ, Triplett BA. Cotton fiber growth in Planta and in vitro. Models for plant cell elongation and Cell Wall biogenesis. Plant Physiol. 2001;127:1361-6.

8. Padmalatha K, Patil D, Kumar K, Dhandapani G, Kanakachari M, Phanindra M, Saravanan K, Mohan T, Jain J, Arkalgud P, Hiremath V, Katageri I, Leelavathi S, Reddy M, Kumar P, Reddy V. Functional genomics of fuzzless-lintless mutant of Gossypium hirsutum L. CV. MCU5 reveal key genes and pathways involved in cotton fibre initiation and elongation. BMC Genomics. 2012;13:624.

9. Schubert A, Benedict C, Gates C, Kohel R. Growth and development of the lint fibers of pima S-4 cotton. Crop Sci. 1976;16:539-43.

10. Arpat AB, Waugh M, Sullivan JP, Gonzales M, Frisch D, Main D, Wood T, Leslie A, Wing RA, Wilkins TA. Functional genomics of cell elongation in developing cotton fibers. Plant Mol Biol. 2004;54(6):911-29.

11. Ji SJ, Lu YC, Feng JX, Wei G, Li J, Shi YH, Fu Q, Liu D, Luo JC, Zhu YX. Isolation and analyses of genes preferentially expressed during early cotton fiber development by subtractive PCR and CDNA array. Nucleic Acids Res. 2003:31(10):2534-43.

12. Tiwari SC, Wilkins TA. Cotton (Gossypium hirsutum) seed trichomes expand via diffuse growing mechanism. Canadian J Bot. 1995;73:746-57.

13. John ME, Keller G. Metabolic pathway engineering in cotton: biosynthesis of polyhydroxybutyrate in fiber cells. Proc Natl Acad Sci. 1996:93:12768-73.

14. Smart LB, Vojdani F, Maeshima M, Wilkins TA. Genes involved in osmoregulation during turgor-driven cell expansion of developing cotton fibers are differentially regulated. Plant Physio. 1998;116:1539-49.

15. Stiff MR, Haigler $\mathrm{CH}$. Recent advances in cotton fiber development. In: Oosterhuis DM, Cothren JT, editors. Flowering and fruiting in cotton. Tennessee: The Cotton Foundation; 2012. p. 163-92.

16. John ME, Crow LJ. Gene expression in cotton (Gossypium Hirsutum L.) fiber: cloning of the mRNAs. Proc Natl Acad Sci U S A. 1992;89:5769-73.

17. Yang S, Cheung F, Lee J, Ha M, Wei N, Sze S, Stelly D, Thaxton P, Triplett B, Town C, Chen Z. Accumulation of genome-specific transcripts, transcription factors and phytohormonal regulators during early stages of fiber cell development in allotetraploid cotton. Plant J. 2006;47(5):761-75.

18. Zhang $M$, Zheng $X$, Song S, Zeng Q, Hou L, Li D, Zhao J, Wei Y, Li X, Luo M, Xiao Y, Luo X, Zhang J, Xiang C, Pei Y. Spatiotemporal manipulation of auxin biosynthesis in cotton ovule epidermal cells enhances fiber yield and quality. Nat Biotechnol. 2011;29(5):453-8.

19. Shi YH, Zhu SW, Mao XZ, Feng JX, Qin YM, Zhang L, Cheng J, Wei LP, Wang ZY, Zhu YX. Transcriptome profiling, molecular biological and physiological studies reveal a major role for ethylene in cotton fiber cell elongation. Plant Cell. 2006:18(3):651-64.

20. Machado A, Wu Y, Yang Y, Llewellyn DJ, Dennis ES. The MYB transcription factor GhMYB25 regulates early fibre and trichome development. Plant J. 2009;59(1):52-62. 
21. Somerville C, Browse J, Jaworski JG, Ohlrogge JB. Lipids. In: Buchanan BB, Gruissem W, Jones RL, editors. Biochemistry \& Molecular Biology of plants. 2nd ed. Somerset: Wiley; 2015. p. 336-400.

22. Benjamini $Y$, Hochberg $Y$. On the adaptive control of the false discovery rate in multiple testing with independent statistics. J Educ Behav Stat. 2000;25(1):60-83.

23. Usadel B, Nagel A, Thimm O, Redestig H, Blaesing OE, Palacios-Rojas N, Selbig J, Hannemann J, Piques MC, Steinhauser D, Scheible WR, Gibon Y, Morcuende R, Weicht D, Meyer S, Stitt M. Extension of the visualization tool MapMan to allow statistical analysis of arrays, display of corresponding genes, and comparison with known responses. Plant Physiol. 2005;138(3):1195-204.

24. Wu Y, Machado A, White R, Llewellyn D, Dennis E. Expression profiling identifies genes expressed early during lint fibre initiation in cotton. Plant Cell Physiol. 2006;47(1):107-27.

25. Taliercio E, Boykin D. Analysis of gene expression in cotton fiber initials. BMC Plant Biol. 2007;7:22.

26. Elliott R, Betzner A, Huttner E, Oakes M, Tucker W, Gerentes D, Perez P, Smyth D. AINTEGUMENTA, an APETALA2-like gene of Arabidopsis with pleiotropic roles in ovule development and floral organ growth. Plant Cell. 1996;8:155-68.

27. Chuck G, Meeley R, Hake $S$. The control of maize spikelet meristem fate by the APETALA2-like gene indeterminate spikelet-1. Genes Dev. 1998;12:1145-54.

28. Moose S, Sisco P. Glossy15, an APETALA2-like gene from maize that regulates leaf epidermal cell identity. Genes Dev. 1996;10:3018-27.

29. Boutilier K, Offringa R, Sharma V, Kieft H, Ouellet T, Zhang L, Hattori J, Liu C, van-Lammeren A, Miki B. Ectopic expression of BABY BOOM triggers a conversion from vegetative to embryonic growth. Plant Cell. 2002;14:1737-49.

30. Licausi F, Ohme-Takagi M, Perata P. APETALA2/ethylene responsive factor (AP2/ERF) transcription factors: mediators of stress responses and developmental programs. New Phytol. 2013;199:639-49.

31. Kurek I, Kawagoe Y, Jacob-Wilk D, Doblin M, Delmer D. Dimerization of cotton fiber cellulose synthase catalytic subunits occurs via oxidation of the zinc-binding domains. Proc Natl Acad Sci. 2002;99:11109-14.

32. Artico S, Nardeli SM, Brilhante O, Grossi-de-Sa MF, Alves-Ferreira M. Identification and evaluation of new reference genes in Gossypium hirsutum for accurate normalization of real-time quantitative RT-PCR data. BMC Plant Biol. 2010;10:49

33. Sun Y, Veerabomma S, Abdel-Mageed HA, Fokar M, Asami T, Yoshida S, Allen RD. Brassinosteroid regulates fiber development on cultured cotton ovules. Plant Cell Physiol. 2005;46(8):1384-91.

34. Liu D, Tu L, Li Y, Wang L, Zhu L, Zhang X. Genes encoding Fasciclin-like Arabinogalactan proteins are specifically expressed during cotton fiber development. Plant Mol Biol Rep. 2008;26:98-113.

35. Qin Y, Hu C, Pang Y, Kastaniotis A, Hiltunen J, Zhu Y. Saturated very-longchain fatty acids promote cotton fiber and Arabidopsis cell elongation by activating ethylene biosynthesis. Plant Cell. 2007;19(11):3692-704.

36. Qin Y, Zhu Y. How cotton fibers elongate: a tale of linear cell-growth mode. Curr Opin Plant Biol. 2011;14:106-11.

37. Sterk P, Booij H, Schellekens GA, Kammen AV, Vries SCD. Cell-specific expression of the carrot EP2 lipid transfer protein gene. Plant Cell. 1991:3:907-21.

38. St Pierre B, Luca VD. Evolution of acyltransferase genes: origin and diversification of the BAHD superfamily of acyltransferases involved in secondary metabolism. In: Romeo JJ, Ibrahim R, Varin L, DeLucca V, editors. Recent Advances in Phytochemistry, 34. Oxford: Elsevier Science; 2000. p. 285-315.

39. Gou J, Yu X, Liu C. A hydroxycinnamoyltransferase responsible for synthesizing suberin aromatics in Arabidopsis. Proc Natl Acad Sci U S A. 2009;106:18855-60.

40. Li Y, Beisson F, Ohlrogge J, Pollard M. Monoacylglycerols are components of root waxes and can be produced in the aerial cuticle by ectopic expression of a suberin-associated acyltransferase. Plant Physiol. 2007;144:1267-77.

41. Kosma D, Molina I, Ohlrogge J, Pollard MM. Identification of an Arabidopsis fatty alcohol: Caffeoyl-coenzyme an acyltransferase required for the synthesis of alkyl hydroxycinnamates in root waxes. Plant Physiol. 2012;160:237-48

42. Tan J, Tu L, Deng F, Hu H, Nie Y, Zhang X. A genetic and metabolic analysis revealed that cotton fiber cell development was retarded by Flavonoid Naringenin. Plant Physiol. 2013;162:86-95.
43. Shu-Hsien HUNG, Chih-Wen YU, Chin Ho LIN. Hydrogen peroxide functions as a stress signal in plants. Bot Bull Acad Sin. 2005:46:1-10.

44. Mei W, Qin Y, Song W, Li J, Zhu Y. Cotton GhPOX1 encoding plant class III peroxidase may be responsible for the high level of reactive oxygen species production that is related to cotton fiber elongation. J Genet Genom. 2009:36:141-50.

45. Zhang D, Zhang T, Guo W. Effect of $\mathrm{H}_{2} \mathrm{O}_{2}$ on fiber initiation using fiber retardation initiation mutants in cotton (Gossypium hirsutum). J Plant Physiol. 2010;167:393.

46. Kudla J, Batistic O, Hashimoto K. Calcium signals: the lead currency of plant information processing. Plant Cell. 2010;22:541-63.

\section{Submit your next manuscript to BioMed Central and we will help you at every step:}

- We accept pre-submission inquiries

- Our selector tool helps you to find the most relevant journal

- We provide round the clock customer support

- Convenient online submission

- Thorough peer review

- Inclusion in PubMed and all major indexing services

- Maximum visibility for your research

Submit your manuscript at www.biomedcentral.com/submit
Biomed Central 